\title{
Exposure Setup and Dosimetry for a Study on Effects of Mobile Communication Signals on Human Hematopoietic Stem Cells in vitro
}

\author{
Martina Rohland $^{1}$, Kai Baaske ${ }^{1}$, Katharina Gläser ${ }^{2}$, Henning Hintzsche ${ }^{2,3}$, Helga Stopper ${ }^{2}$, \\ Thomas Kleine-Ostmann ${ }^{1}$, and Thorsten Schrader ${ }^{1}$ \\ ${ }^{1}$ Physikalisch-Technische Bundesanstalt (PTB), Bundesallee 100, 38116 Braunschweig, Germany \\ ${ }^{2}$ Institut für Pharmakologie und Toxikologie, Universität Würzburg, Versbacher Str. 9, 97078 Würzburg, Germany \\ ${ }^{3}$ present address: Bavarian Health and Food Safety Authority, Eggenreuther Weg 43, 91058 Erlangen, Germany \\ Correspondence to: Thomas Kleine-Ostmann (thomas.kleine-ostmann@ptb.de)
}

Received: 21 December 2016 - Revised: 26 April 2017 - Accepted: 31 July 2017 - Published: 21 September 2017

\begin{abstract}
In this paper we describe the design of an exposure setup used to study possible non-thermal effects due to the exposure of human hematopoietic stem cells to GSM, UMTS and LTE mobile communication signals. The experiments are performed under fully blinded conditions in a TEM waveguide located inside an incubator to achieve defined environmental conditions as required for the living cells. Chamber slides containing the cells in culture medium are placed on the septum of the waveguide. The environmental and exposure parameters such as signal power, temperatures, relative humidity and $\mathrm{CO}_{2}$ content of the surrounding atmosphere are monitored permanently during the exposure experiment. The power of the exposure signals required to achieve specific absorption rates of $0.5,1,2$ and $4 \mathrm{~W} \mathrm{~kg}^{-1}$ are determined by numerical calculation of the field distribution inside the cell culture medium at $900 \mathrm{MHz}$ (GSM), $1950 \mathrm{MHz}$ (UMTS) and $2535 \mathrm{MHz}$ (LTE). The dosimetry is verified both with scattering parameter measurements on the waveguide with and without containers filled with cell culture medium and with temperature measurements with nonmetallic probes in separate heating experiments.
\end{abstract}

\section{Introduction}

The widespread use of mobile communication technologies such as GSM (Global System for Mobile Communications), UMTS (Universal Mobile Telecommunications System) and LTE (Long-Term-Evolution) means that many people are fre- quently exposed to electromagnetic radiation. As the mobile phone is held close to the human body, this represents the main exposure source. Despite the very large number of studies on radio-frequency bio-electromagnetic interaction in diverse systems (see, e.g, Vian et al., 2016), it is still controversial whether non-thermal effects exist, especially regarding long-term adverse health effects in humans with long symptom-free latency periods and effects specific to children (Feychting, 2011). To contribute to this discussion, we examined potential effects of communication signals on human hematopoietic stem cells in an in vitro study financed by the German Federal Office for Radiation Protection (Bundesamt für Strahlenschutz - BfS). Earlier studies have shown that exposure to continuous-wave signals in the frequency range of interest leads to mitotic disturbances (Schrader et al., 2008, 2011) but not to genotoxic effects (Hintzsche et al., 2012). Under the given experimental conditions, this study did not reveal significant changes in the chosen end points which are apoptosis, oxidative stress, cell cycle and DNA damage and repair (Gläser et al., 2016).

For the exposure experiments, test signals based on the mobile phone standards GSM, UMTS and LTE are generated with a vector signal generator, amplified and fed into a coaxial transversal electromagnetic field waveguide as field generator (a so called $\mu$ TEM cell, which is used to generate calculable field strengths for field probe calibration traceable to the international system of units, Münter et al., 1995). In order to establish defined environmental conditions as needed by the cells, the $\mu$ TEM cell containing the chamber slides is placed inside an incubator. A software is written to auto- 
mate the field exposure. It allows to establish a fully blinded procedure where the person preparing and evaluating the biological samples does not know under which conditions the samples are exposed. In order to determine the signal power needed for GSM, UMTS and LTE exposure to achieve the intended specific absorption rates (SAR) of $0.5,1,2$ and $4 \mathrm{~W} \mathrm{~kg}^{-1}$, the field distribution is simulated inside the chamber slides filled with cell culture medium as positioned in the $\mu$ TEM cell. The SAR values are obtained by a numerical calculation using the CST computer program system Microwave Studio $^{\mathrm{TM}}$ (CST, 2010).

In this paper we show details of the exposure setup and procedures in Sect. 2. The numerical field calculations and the procedures needed to set the required output power of the signal generator to achieve the intended SAR values are discussed in Sect. 3. In Sect. 4 verification experiments based on vector network analysis and temperature measurements are shown that demonstrate the validity of the SAR values. Finally, conclusions are drawn in Sect. 5.

\section{Exposure Experiment}

\subsection{Signals}

Test signals based on the mobile phone standards of 2nd generation (GSM), 3rd generation (UMTS) and 4th generation (LTE) are used for the exposure experiments. The test signals are synthesized using a Rohde and Schwarz SMBV $100 \mathrm{~A}^{\mathrm{TM}}$ vector signal generator.

The exposure experiment with GSM signals $(900 \mathrm{MHz})$ aims at resembling the exposure during a regular call with a mobile phone. According to the 3rd Generation Partnership Project specifications (3GPPa, 2012), arbitrary bit sequences are transmitted using time slots. The frequency range of the uplink to the base station is restricted to frequencies between 890 and $915 \mathrm{MHz}$ in 124 channels. It comprises the $217 \mathrm{~Hz}$ pulsing within the time division multiple access (TDMA) time frame as well as the $1733 \mathrm{~Hz}$ pulsing of the single time slots and the $270.8 \mathrm{kHz}$ pulsing of the single bits (Schüller et al., 2000). As the output power of the vector signal generator is not sufficient to achieve higher SAR values with only one time slot activated (which would be most realistic considering the situation during a phone call), all eight time slots are activated instead.

For UMTS exposure $(1950 \mathrm{MHz})$, a generic test signal with pseudo noise sequence data transmission and increased lower frequency content is chosen as realistic signal. In particular, a signal according to 3GPP Specifications TS 25.141 (3GPPb, 2012) with continuous Wideband Code Division Multiple Access (WCDMA) uplink signal including control channel (Dedicated Physical Control Channel - DPCCH) and data channel (Dedicated Physical Data CHannel - DPDCH) for a single user equipment is selected. A $60 \mathrm{kBits}^{-1}$ channel for the simulation of a simple pure (a)

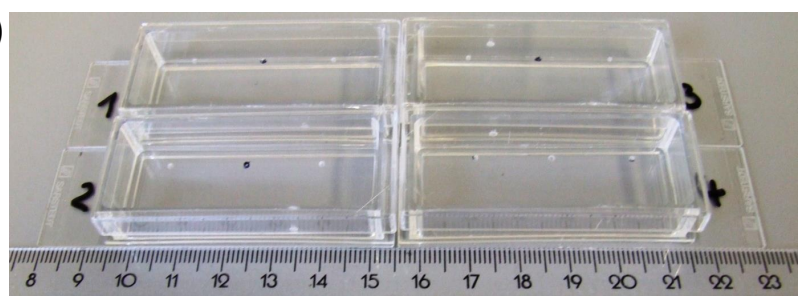

(b)

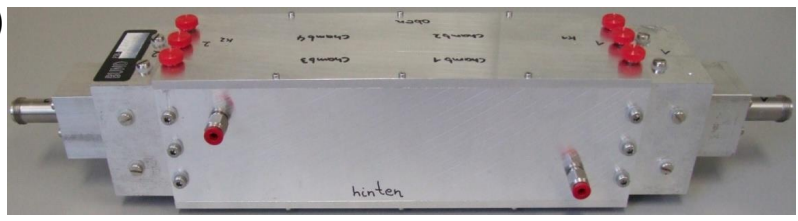

(c)

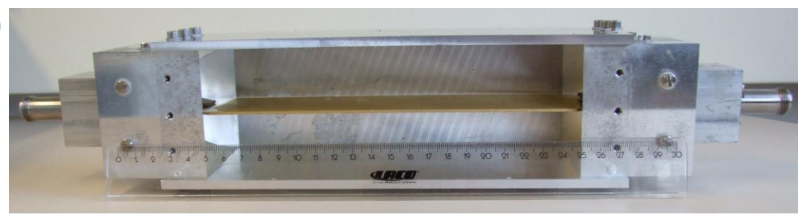

Figure 1. (a) Four 1-well tissue culture PCA chamber slides as placed on the septum, (b) coaxial transversal electromagnetic field waveguide ( $\mu$ TEM cell) used as field generator, and (c) view onto the septum of the opened field generator. (a)

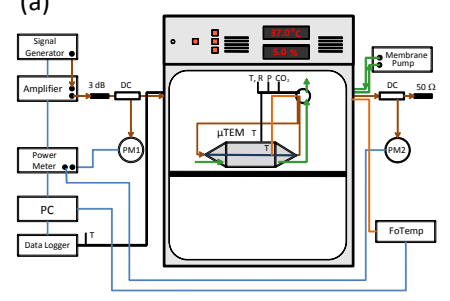

(b)

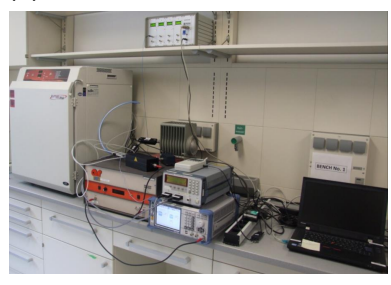

Figure 2. (a) Schematic and (b) photograph of the exposure setup.

speech channel and a $12.2 \mathrm{kBit} \mathrm{s}^{-1}$ reference measurement channel (uplink signal) are established.

For LTE (2535 MHz), a typical load scenario comprises high bandwidth and high payload. This corresponds to a fast variation of the states in the constellation diagram. Therefore a pseudo-random-bit-sequence (PRBS) is used. As specified in 3GPP Specifications TS 36.141 (ETSI, 2011, 3GPPc, 2012) a reference sensitivity test case of the LTE Test Case Wizard $^{\mathrm{TM}}$ (a software tool running on the Rohde and Schwarz SMBV $100 \mathrm{~A}^{\mathrm{TM}}$ to setup test cases) is used to mimic a typical single user equipment. A broad LTE channel with $20 \mathrm{MHz}$ bandwidth in the uplink is implemented using five of the overall available 100 resource blocks.

\subsection{Exposure Apparatus}

In order to expose the cell cultures to electromagnetic fields (EMF) whose properties resemble those in the far-field of an antenna, we use a coaxial waveguide which has a transver- 


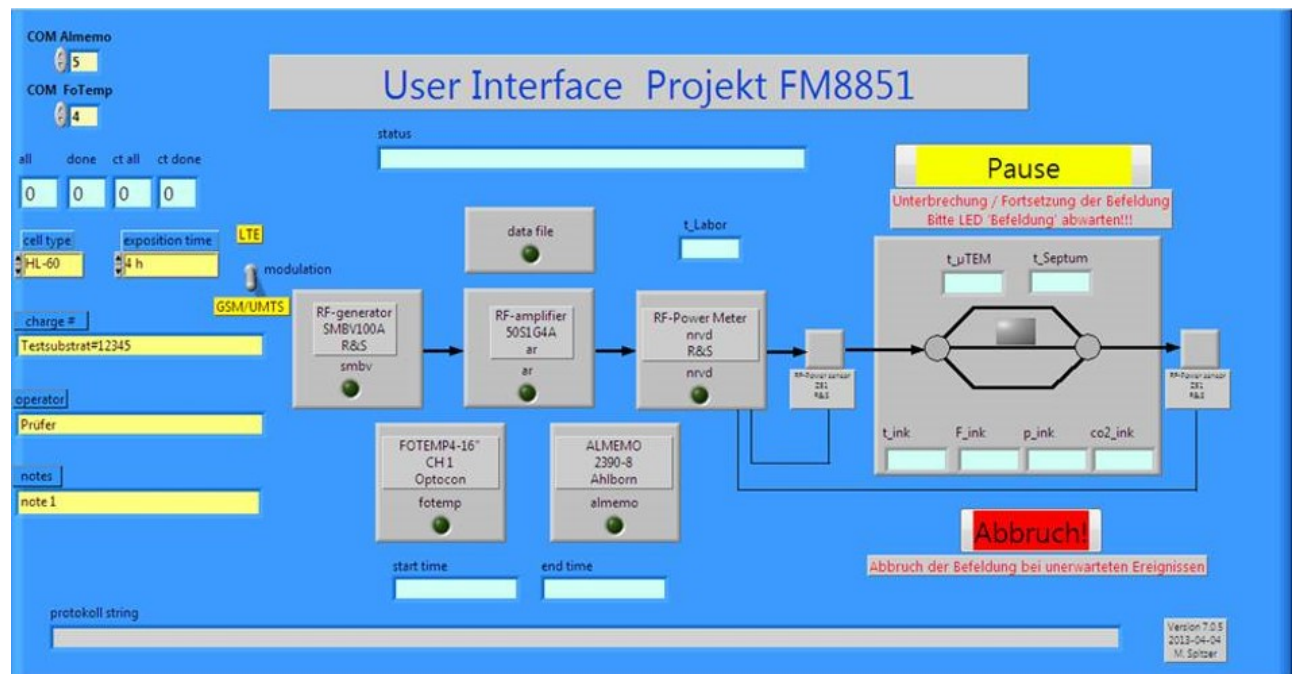

Figure 3. User interface of the LabView ${ }^{\mathrm{TM}}$ program used to control the exposure setup.

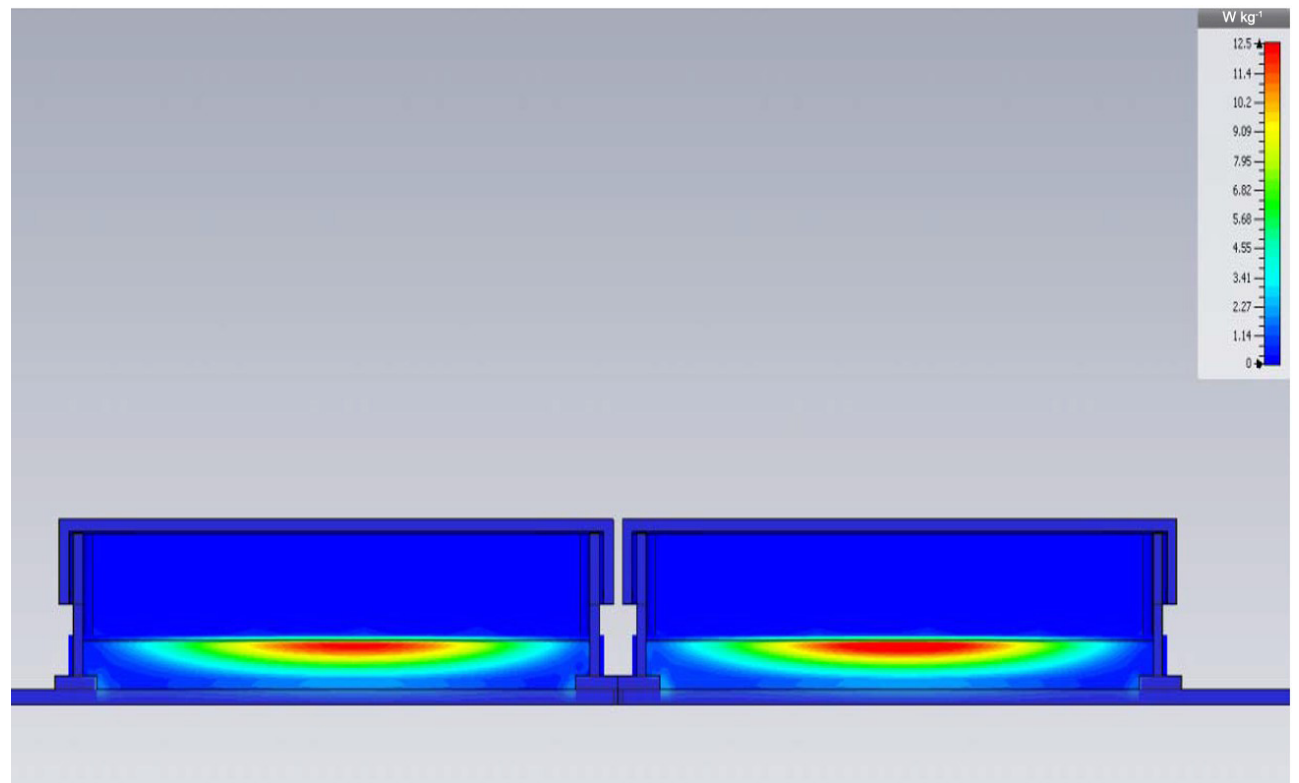

Figure 4. The CST simulation with four sample containers shows the variation of the root-mean-square SAR value at $1950 \mathrm{MHz}$ with $1 \mathrm{~W}$ effective input power. Shown is a cut along the propagation direction along the center of two adjacent sample containers.

sal electromagnetic (TEM) field structure. The TEM waveguide used here is a modified (prolonged) version of a so called $\mu$ TEM cell, which is used to generate calculable field strengths for field probe calibration traceable to the international system of units SI (Münter et al., 1995). Four 1-well tissue culture PCA chamber slides (Fig. 1a, Sarstedt AG and Co., Nümbrecht, Germany, size $76 \mathrm{~mm} \times 24 \mathrm{~mm} \times 12 \mathrm{~mm}$ ) are placed on the septum, which is the inner conductor of the TEM waveguide (Fig. 1b and c). The assessable volume on top of the septum with a nearly homogeneous field distribution in case it is unloaded has a dimension of approximately $200 \mathrm{~mm} \times 60 \mathrm{~mm} \times 35 \mathrm{~mm}$. The $\mu$ TEM cell can be operated up to frequencies of several $\mathrm{GHz}$, however, at $1.6 \mathrm{GHz}$ and above waveguide modes occur at distinct frequencies for which the field structure deviates from TEM conditions.

In order to establish defined atmospheric conditions as needed by the living cells, the $\mu$ TEM cell containing the chamber slides is placed inside an incubator. A membrane pump is used to draw the incubator atmosphere through the $\mu$ TEM cell housing and feed it back in the incubator afterwards. Figure 2 shows a schematic together with a photograph of the setup.

The GSM, UMTS or LTE modulated radio frequency (RF) signal from the vector signal generator (Rohde and 

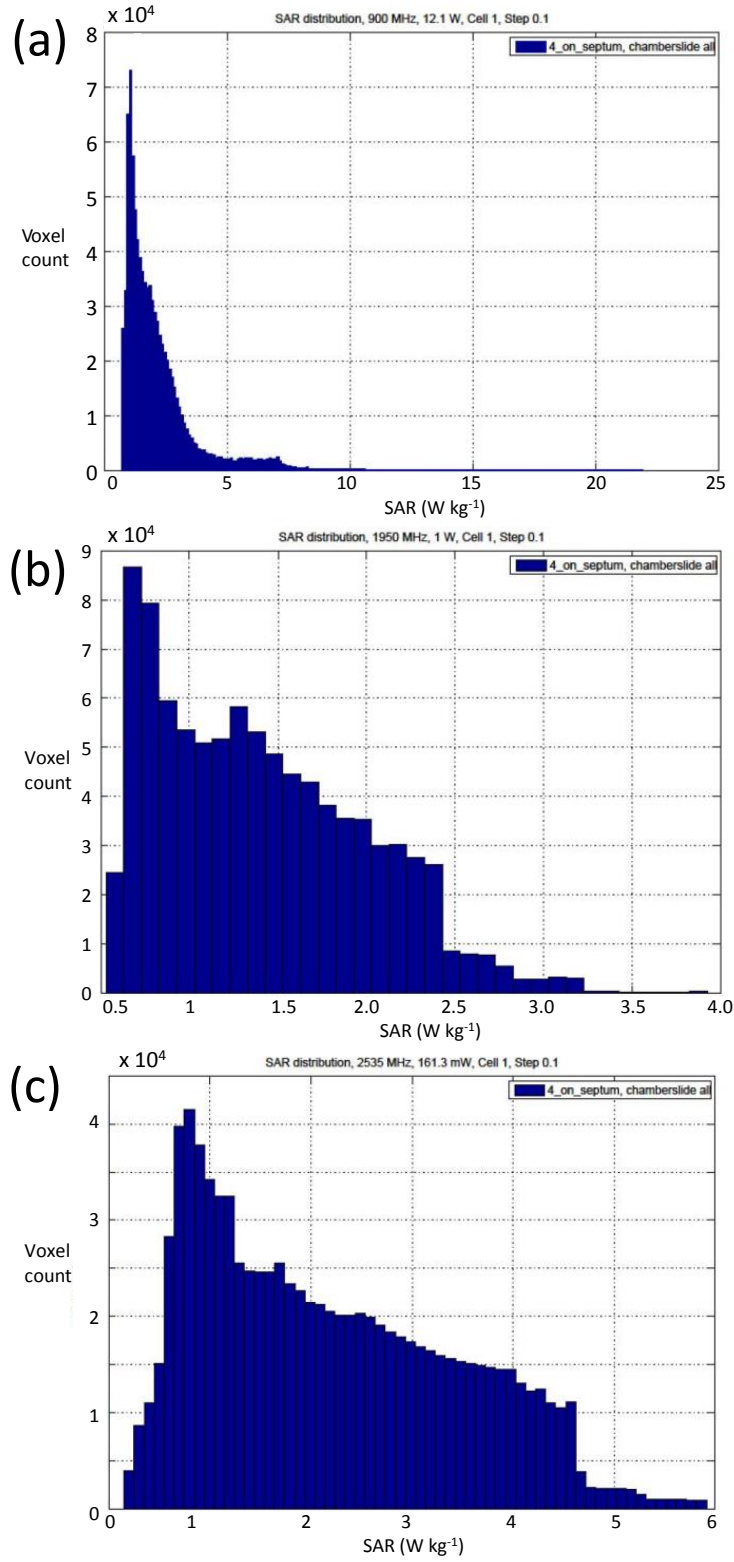

Figure 5. Histograms of SAR values in medium (volume of $1 \mathrm{~mm}$ height at the bottom only) in chamber slide 1 for (a) GSM (900 MHz) and an input power of $12.1 \mathrm{~W}$, (b) UMTS (1950 MHz) and an input power of $1 \mathrm{~W}$, and (c) LTE (2535 MHz) and an input power of $163.1 \mathrm{~mW}$.

Schwarz SMBV 100A ${ }^{\mathrm{TM}}$ ) is amplified (Amplifier Research AR 50S1G4A ${ }^{\mathrm{TM}}$ ), fed through the $\mu$ TEM cell and then dissipated in a $50 \Omega$ matching load. Two directional couplers (DC) located before and after the $\mu$ TEM cell are used to couple out part of the signal to measurement heads (PM1 and PM2) for RF power. Data logger sensors (Alborn Almemo ${ }^{\mathrm{TM}}$ ) are used to monitor temperature $T$ (in $\mu$ TEM cell housing, incubator atmosphere and laboratory air), relative humidity $R$ (in incubator atmosphere), pressure $P$ (in incubator atmo-
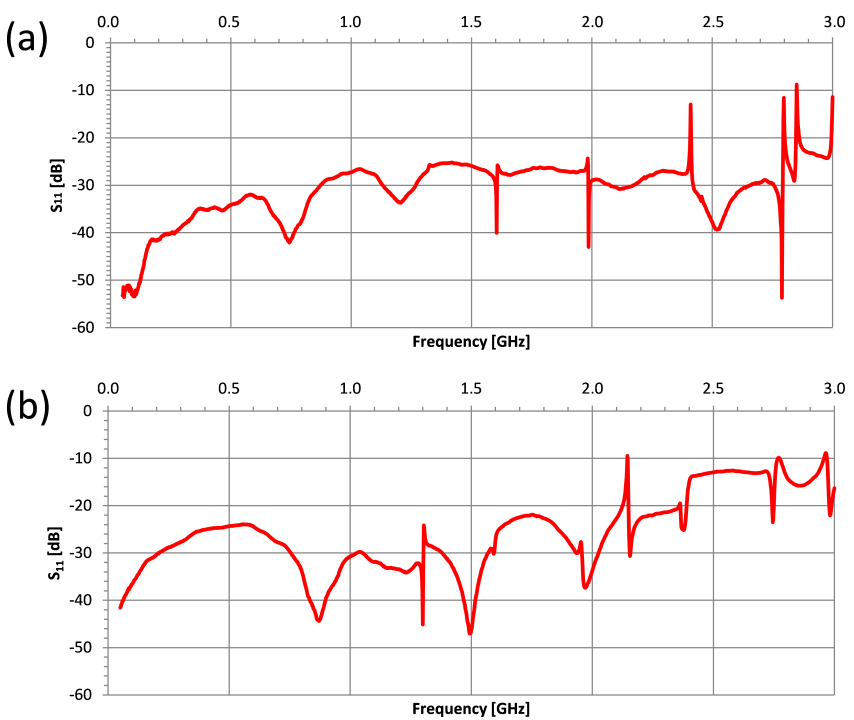

Figure 6. Input reflexion factor $S_{11}$ for (a) the empty $\mu$ TEM cell and (b) the $\mu$ TEM cell loaded with four cell containers filled with cell culture medium.

(a)

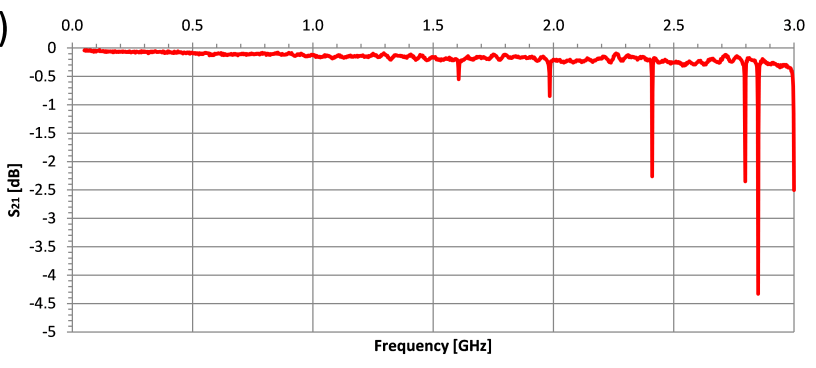

(b)

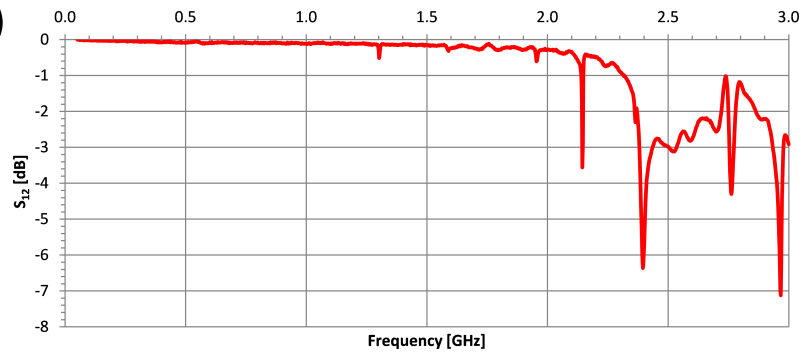

Figure 7. Transmission factor $S_{21}$ for (a) the empty $\mu$ TEM cell and (b) the $\mu \mathrm{TEM}$ cell loaded with four cell containers filled with cell culture medium.

sphere) and $\mathrm{CO}_{2}$ content (in incubator atmosphere). In addition, the septum temperature of $\mu$ TEM cell is measured using a metal-free fibre optic thermometer (Optocon FoTemp $4^{\mathrm{TM}}$ with probe $\mathrm{TK} 5 / 2,0.55 \mathrm{~mm}$ thickness with proven biological compatibility) in order not to disturb the field structure within the $\mu$ TEM cell. For dosimetric experiments outside the regular exposure campaigns, it is also used to measure the temperature of the cell culture medium inside a chamber slide during exposure. A personal computer (PC) is used 
to control signal generator and amplifier and to read out the power meter, the data logger and the fibre optic thermometer.

\subsection{Procedure and Software}

A LabView ${ }^{\mathrm{TM}}$ program is written to automate the field exposure. Figure 3 shows the user interface developed to control the exposure setup. It allows to establish a fully blinded procedure for field exposure where the person preparing and evaluating the biological samples does not know under which conditions the samples are exposed. The program arbitrarily choses from a pool of exposures that are to be performed. Labelled by number of the exposed samples, it saves the exposure conditions together with the logged environmental conditions to a file which is not accessible by the operating person. This file is not made available to the person evaluating the biological endpoints before the data analysis is finalized. While the exposure setup is located at the University of Würzburg, correct functioning of the program and the setup, appropriateness of environmental parameters and secure data file handling are guaranteed via remote login from Physikalisch-Technische Bundesanstalt (PTB) in Braunschweig. Altogether, more than 180 exposures were undertaken in this setup as part of the study based on three different signals, five different power levels (including $0 \mathrm{~W} \mathrm{~kg}^{-1}$ ), two different cell lines, two different exposure durations and three independent replica.

\section{Numerical Field Calculation for Dosimetry}

In order to determine the signal power needed at 900, 1950 and $2535 \mathrm{MHz}$ to achieve SAR values of $0.5,1,2$ and $4 \mathrm{~W} \mathrm{~kg}^{-1}$, the field distribution is simulated inside the chamber slides filled with cell culture medium as positioned in the field generator. The SAR values are obtained by a numerical calculation using the CST computer program system Microwave Studio ${ }^{\mathrm{TM}}$ (CST, 2010) based on the finite integration technique. The calculations refer to SAR values obtained for $0.001 \mathrm{~g}$ mass elements based on the rootmean-square (RMS) power. The simulations based on a 3-D computer model and on material parameters taken from literature $\left(\left(\varepsilon_{r \text {,air }}=1.00059 ; \varepsilon_{r \text {, media }}=78.4, \varepsilon_{r \text {,slide }}=2.3\right)\right.$ are performed at $900 \mathrm{MHz}$ for GSM exposure, $1950 \mathrm{MHz}$ for UMTS exposure and $2535 \mathrm{MHz}$ for LTE exposure using the time-domain solver. We observed no significant coupling between the sample containers (see e.g. Collin, 2007; Lallechere et al., 2010). The field distributions do not depend perceptibly on whether other containers are placed in the vicinity or not. As an example, Fig. 4 shows the results for the simulation at $1950 \mathrm{MHz}$.

From SAR distributions calculated with Microwave Studio $^{\text {TM }}$, histograms are extracted and the strength of exposure is evaluated using mean and standard deviation as done by Schönborn (Schönborn et al., 2001). The SAR dis- tribution inside one sample container is random with various statistical distributions (Berdinas-Torres, 2007). It can be assumed that the cells within the medium are concentrated in the lower $1 \mathrm{~mm}$ of the overall $3.5 \mathrm{~mm}$ of cell suspension after some time. Hence, the SAR values are evaluated for the bottom of the chamber slide, only. Figure 5 shows histograms extracted from the SAR distribution calculated at 900, 1950 and $2535 \mathrm{MHz}$.

With a voxel size of $0.1 \mathrm{~mm} \times 0.1 \mathrm{~mm} \times 0.1 \mathrm{~mm}$, the volume where the cells are located comprises 918.000 SAR values in a single sample container. All four chamber slides contribute 3.672.000 values to a single histogram used for the determination of mean and standard deviation for each frequency. As the proportionality between feed power and specific absorption rate allows for linear scaling, the feed power is chosen as appropriate for the simulations. The results are scaled in such a way to relate the mean of the histograms to the input feed power determining the required feed powers for SAR values of $0.5,1,2$ and $4 \mathrm{~W} \mathrm{~kg}^{-1}$.

Table 1 shows the resulting required feed power for the SAR values of $0.5,1,2$ and $4 \mathrm{~W} \mathrm{~kg}^{-1}$ for GSM $(900 \mathrm{MHz})$, UMTS $(1950 \mathrm{MHz})$ and LTE $(2535 \mathrm{MHz})$ exposure.

The mean values from the histograms corresponding to the calculated SAR distributions (relative standard deviations given in Table 1) are used to find the feed power into the $\mu$ TEM cell required to achieve the nominal SAR values. From these power levels, the required vector signal generator output power is determined taking into account cable losses and amplifier gain. It should be noted that the feed power required to achieve $4 \mathrm{~W} \mathrm{~kg}^{-1}$ in the cell medium is considerably lower for UMTS and even more for LTE. This can be attributed to the strong absorption observed in water for microwaves with frequencies close to $2.45 \mathrm{GHz}$. Despite the same SAR values for all signal types, the temperature increase measured in a separate experiment after exposure corresponding to $4 \mathrm{~W} \mathrm{~kg}^{-1}$ is different. It should be noted that the SAR values used to set exposure strength are calculated from the field distribution in the lowest $1 \mathrm{~mm}$ of medium, whereas the temperature increase in the whole sample depends on heat transfer from and to the septum (the septum temperature depends mainly on Ohmic losses and is higher for higher feed powers) and also on the average SAR value for the whole sample volume.

\section{Verification of Dosimetry}

Both, measurements of the transmission scattering parameters of empty and loaded $\mu$ TEM cell and temperature measurements with a metal free thermometer immersed into cell culture medium during separate exposure experiments are used to estimate the heat transfer into the sample volume. In all cases of exposure the sample temperature remained well below $39^{\circ} \mathrm{C}$ and is considered not to be significant for the biological endpoints. 
Table 1. Required signal power to achieve SAR values of $0.5,1,2$, and $4 \mathrm{~W} \mathrm{~kg}^{-1}$.

\begin{tabular}{|c|c|c|c|c|c|c|}
\hline Frequency & $\begin{array}{r}\text { Targeted } \\
\text { SAR value } \\
\left(\mathrm{W} \mathrm{kg}^{-1}\right)\end{array}$ & $\begin{array}{r}\text { Relative standard } \\
\text { deviation of } \\
\text { calculated SAR } \\
\text { distribution }\end{array}$ & $\begin{array}{r}\text { Feed Power } \\
\text { into } \mu \text { TEM } \\
\text { cell } \\
(\mathrm{W})\end{array}$ & $\begin{array}{r}\text { Feed Power } \\
\text { into } \mu \text { TEM } \\
\text { cell } \\
(\mathrm{dBm})\end{array}$ & $\begin{array}{r}\text { Amplification } \\
\text { minus cable } \\
\text { losses } \\
(\mathrm{dB})\end{array}$ & $\begin{array}{r}\text { Power at } \\
\text { Generator } \\
(\mathrm{dBm})\end{array}$ \\
\hline \multirow{4}{*}{900} & 4 & $43 \%$ & 21.8 & 43.4 & 52.5 & -9.13 \\
\hline & 2 & $43 \%$ & 10.9 & 40.4 & 52.5 & -12.08 \\
\hline & 1 & $43 \%$ & 5.45 & 37.4 & 52.3 & -14.92 \\
\hline & 0.5 & $43 \%$ & 2.73 & 34.4 & 52.2 & -17.75 \\
\hline \multirow{4}{*}{1950} & 4 & $71 \%$ & 2.8 & 34.5 & 50.5 & -16.01 \\
\hline & 2 & $71 \%$ & 1.4 & 31.5 & 51.0 & -19.52 \\
\hline & 1 & $71 \%$ & 0.7 & 28.5 & 51.0 & -22.47 \\
\hline & 0.5 & $71 \%$ & 0.35 & 25.5 & 51.0 & -25.44 \\
\hline \multirow{4}{*}{2535} & 4 & $60 \%$ & 0.2904 & 24.6 & 51.4 & -26.83 \\
\hline & 2 & $60 \%$ & 0.1452 & 21.6 & 51.4 & -29.84 \\
\hline & 1 & $60 \%$ & 0.0726 & 18.6 & 51.1 & -32.52 \\
\hline & 0.5 & $60 \%$ & 0.0363 & 15.6 & 51.1 & -35.49 \\
\hline
\end{tabular}

Table 2. Estimated average SAR values for whole sample medium estimated from scattering parameters and temperature increase in cell medium due to maximum exposure measured in a separate experiment.

\begin{tabular}{lrlrr}
\hline Frequency & $\begin{array}{r}\text { Targeted SAR } \\
\text { value in lower } \\
\text { mm of medium }\end{array}$ & $\begin{array}{l}\text { Feed Power } \\
\text { into } \mu \text { TEM cell }\end{array}$ & $\begin{array}{r}\text { Average SAR value for } \\
\text { whole medium } \\
\text { estimated from }\end{array}$ & $\begin{array}{r}\text { Temperature } \\
\text { increase } \\
\text { scattering parameters } \\
\left(\mathrm{W} \mathrm{kg}^{-1}\right)\end{array}$ \\
\hline 900 & $\left(\mathrm{~W} \mathrm{~kg}^{-1}\right)$ & $(\mathrm{W})$ & 12.41 & $1.7 \pm 0.15$ \\
1950 & 4 & 21.8 & 8.63 & $1.8 \pm 0.15$ \\
2535 & 4 & 2.8 & 9.24 & $0.2 \pm 0.15$ \\
\hline
\end{tabular}

\subsection{Scattering Parameters}

A simple power budget can be used to estimate the radio frequency absorption $P_{\mathrm{abs}}$ in the sample from measurements of the $\mu$ TEM cell scattering parameters with $\left(S_{21}\right.$ loaded, $\left.S_{11 \text { loaded }}\right)$ and without $\left(S_{21 \text { empty }}, S_{11 \text { empty }}\right)$ and the input power $P_{\text {in }}$ :

$P_{\mathrm{abs}}=$

$P_{\text {in }} \cdot\left(\left|S_{21 \text { empty }}\right|^{2}-\left|S_{21 \text { loaded }}\right|^{2}+\left|S_{11 \text { empty }}\right|^{2}-\left|S_{11 \text { loaded }}\right|^{2}\right)$.

From this the average SAR value for the whole cell medium in all four containers of mass $m=12 \mathrm{~g}$ can be estimated using:

$\mathrm{SAR}=\frac{P_{\mathrm{abs}}}{m}$.

Figure 6 shows the reflexion and Fig. 7 the transmission scattering parameter measurements used for this estimate. Despite the fact that the simple power budget does not take changes of the field pattern into account when loading the cell (and therefore does not take into account that the Ohmic losses of the $\mu$ TEM cell itself change), the estimated SAR values reported in Table 2 show that the dosimetry used in this campaign is realistic. The average SAR value in the whole sample medium is $2-3$ fold higher than the SAR value in the lower mm of cell medium at the bottom. However, the average SAR values are in the same order of magnitude independent of frequency, which is consistent with the SAR values calculated from the field distributions.

\subsection{Temperature Measurements}

The metal-free fibre optic thermometer (Optocon FoTemp4 ${ }^{\mathrm{TM}}$ with probe $\mathrm{TK} 5 / 2,0.55 \mathrm{~mm}$ thickness) is used to measure the temperature increase during exposure without disturbing the field structure in a separate experiment with cell culture medium, only. As reported in Table 2, the temperature increase at maximum exposure (targeted SAR value of $4 \mathrm{~W} \mathrm{~kg}^{-1}$ in the lower mm of cell culture medium) is much higher for GSM and UMTS exposure than for LTE exposure although the SAR values are similar (both for the whole sample and in the lower mm of liquid) while the input power 
differs by a factor of 75 between GSM and LTE. Obviously, the observed heating depends not only on the heat deposition due to absorption in the sample, but also on heating due to Ohmic losses in the $\mu$ TEM cell and the heat transfer between samples and $\mu$ TEM cell septum affected by temperature differences.

\section{Conclusions}

We have shown the design of a field exposure apparatus that is used to study effects of mobile communication signals on human hematopoietic stem cells in vitro. The samples are exposed to modulated electromagnetic fields under far field conditions by placing them onto the septum of a TEM waveguide surrounded by the atmosphere of an incubator. A software allows for a fully blinded exposure procedure and permanent monitoring of the exposure conditions. Different SAR values in the samples between 0 and $4 \mathrm{~W} \mathrm{~kg}^{-1}$ are set by adjusting the feed power into the $\mu$ TEM cell based on numeric field calculations. The dosimetry is verified both with scattering parameter measurements on the empty and loaded $\mu$ TEM cell and with temperature measurements in cell culture medium.

Data availability. The underlying primary data sets are not publicly available as proprietary software would be needed for assessment and large efforts for documentation would be required (contact person: Thomas Kleine-Ostmann, e-mail: thomas.kleineostmann@ptb.de).

Competing interests. The authors declare that they have no conflict of interest.

Acknowledgements. This work was funded by the Federal Office for Radiation Protection (Bundesamt für Strahlenschutz - BfS), Germany. The authors thank Meinhard Spitzer for programming the LabView ${ }^{\text {TM }}$ code.

Edited by: Lars Ole Fichte

Reviewed by: Robert Hollan and two anonymous referees

\section{References}

3GPPa: 3rd Generation Partnership Project (3GPP), Specifications, last visit, http://www.3gpp.org/ftp/Specs/latest/Rel-10/51_ series/ (last access: 9 December 2016), 2012.

3GPPb: 3rd Generation Partnership Project (3GPP), Specifications, last visit, http://www.3gpp.org/ftp/Specs/latest/Rel-10/34_ series/ (last access: 9 December 2016), 2012.

3GPPc: 3rd Generation Partnership Project (3GPP), Specifications, last visit, http://www.3gpp.org/ftp/Specs/latest/Rel-10/36_ series/ (last access: 9 December 2016), 2012.
Berdinas-Torres, V. J.: Exposure's systems and dosimetry of large scale in vivo studies, $\mathrm{PhD}$ thesis, Swiss Federal Institute of Technology, Zurich, Switzerland, 2007.

Collin, A.: Dosimétrie de systèmes d'exposition pour l'étude in vivo ou in vitro des interactions des ondes électromagnétiques décimétriques et centimétriques avec le vivant, $\mathrm{PhD}$ Thesis, Université de Limoges, Limoges, France, 2007 (in French).

CST Microwave Studio, http://www.CST.de/ (last access: 9 December 2016), Version 2010, 2010.

ETSI TS 129277 V10.0.0: Universal Mobile Telecommunications System (UMTS); LTE; Optimised handover procedures and protocol between EUTRAN access and non-3GPP accesses (S102); Stage 3 (3GPP TS 29.277 version 10.0.0 Release 10), 2011.

Feychting, M.: Mobile phones, radiofrequency fields, and health effects in children-epidemiological studies, Prog. Biophys. Mol Bio., 107, 343-348, 2011.

Gläser, K., Rohland, M., Kleine-Ostmann, T., Schrader, T., Stopper H., and Hintzsche, H.: Effect of Radiofrequency Radiation on Human Hematopoietic Stem Cells, Rad Research, 186, 455-465, https://doi.org/10.1667/RR14405.1, 2016.

Hintzsche, H., Jastrow, C., Kleine-Ostmann, T., Schrader, T., and Stopper, H.: $900 \mathrm{MHz}$ radiation does not induce micronucleus formation in different cell types, Mutagenesis, 27, 477-483, 2012.

Lallechere, S., Girard, S., Roux, D., Bonnet, P., Paladian, F., and Vian, A., Mode stirred reverberation chamber (MSRC): a large and efficient tool to lead high frequency bioelectromagnetic in vitro experimentation, PIER, 2010.

Münter, K., Schräder, T., Spitzer, M., and Glimm, J.: Rückführbare Messungen elektromagnetischer Felder, Tech. Mess., 2, 44-48, 1995.

Schönborn, F., Poković, K., Burkhardt, M., and Kuster, N.: Basis for Optimization of In Vitro Exposure Apparatus for Health Hazard Evaluations of Mobile Communications, Bioelectromagnetics, 22, 547-559, 2001.

Schrader, T., Münter, K., Kleine-Ostmann, T., and Schmid, E.: Spindle disturbances in human-hamster hybrid $\left(\mathrm{A}_{L}\right)$ cells induced by mobile communication frequency range signals, Bioelectromagnetics, 29, 626-639, 2008.

Schrader, T., Kleine-Ostmann, T., Münter, K., Jastrow, C., and Schmid, E.: Spindle disturbances in human-hamster hybrid $\left(\mathrm{A}_{L}\right)$ cells induced by the electrical component of the mobile communication frequency range signal, Bioelectromagnetics, 32, 291301, 2011.

Schüller, M., Streckert, J., Bitz, A., Menzel, K., and Eicher, B.: Proposal for generic GSM test signal, Proc. 22nd BEMS Annual Meeting, Munich, Germany, 122-123, 2000.

Vian, A., Davies, E., Gendraud, M., and Bonnet, P.: Plant Responses to High Frequency Electromagnetic Fields, BioMed Research International, 2016, 1830262, https://doi.org/10.1155/2016/1830262, 2016. 